\title{
The Urban Built Environment and Mobility in Older Adults: A Comprehensive Review
}

\author{
Andrea L. Rosso, Amy H. Auchincloss, and Yvonne L. Michael \\ Department of Epidemiology and Biostatistics, Drexel University School of Public Health, 1505 Race Street, Mail Stop 1033, \\ Bellet 6th Floor, Philadelphia, PA 19102, USA \\ Correspondence should be addressed to Andrea L. Rosso, alr44@drexel.edu
}

Received 16 December 2010; Accepted 3 May 2011

Academic Editor: Thomas R. Prohaska

Copyright ( $\odot 2011$ Andrea L. Rosso et al. This is an open access article distributed under the Creative Commons Attribution License, which permits unrestricted use, distribution, and reproduction in any medium, provided the original work is properly cited.

\begin{abstract}
Mobility restrictions in older adults are common and increase the likelihood of negative health outcomes and premature mortality. The effect of built environment on mobility in older populations, among whom environmental effects may be strongest, is the focus of a growing body of the literature. We reviewed recent research (1990-2010) that examined associations of objective measures of the built environment with mobility and disability in adults aged 60 years or older. Seventeen empirical articles were identified. The existing literature suggests that mobility is associated with higher street connectivity leading to shorter pedestrian distances, street and traffic conditions such as safety measures, and proximity to destinations such as retail establishments, parks, and green spaces. Existing research is limited by differences in exposure and outcome assessments and use of cross-sectional study designs. This research could lead to policy interventions that allow older adults to live more healthy and active lives in their communities.
\end{abstract}

\section{Introduction}

Mobility limitations are defined by impairment or dependence in movement and affect between one third and one half of adults aged 65 or older [1]. Mobility limitations can affect an individual's health through a number of pathways. Lack of physical activity in older individuals can lead to loss of muscle mass (sarcopenia), loss of bone density (osteoporosis), and an increase in fat mass (obesity) [2, 3]. Isolation and loss of social ties resulting from reduced mobility can lead to depression and other adverse mental health outcomes [4]. A lack of access to resources such as fresh foods and medical care which can result from limited mobility can also have negative impacts on health [5]. Individuals with mobility limitations are also at higher risk of health service utilization [6-8] and institutionalization $[6,9,10]$. Ultimately, further frailty and disability and an increased risk of premature mortality can result from restricted mobility $[1,11]$.

Methods of assessing mobility limitations vary [1]. In assessment of mobility, it is important to distinguish between capacity to function - what an individual could do-and enacted function-what an individual does do [12]. In this way, assessments of an individual's walking behavior represent an enacted form of mobility while questions that assess an individual's perception of their ability represent functional capacity. Both may be relevant measures of mobility.

Mobility restrictions are not typically the result of a single cause, but arise from an interaction of risk factors in various domains, both individual and environmental [1]. Traditionally, disability research had been based on the medical model in which the focus is on the individual and pathology [13]. More recently, following on the work of Lawton [14, 15], Verbrugge and Jette [16], and the World Health Organization's International Classification of Functioning, Disability, and Health (ICF) [17], disability models have focused on the interaction of the individual with their environment. Lawton stressed the importance of the environment in determining the well-being of older adults where an individual's competence to deal with their environment combines with the stresses, or press, that the environment places on that individual [14]. Thus, Lawton's model adds the possibility that mobility may be enhanced 
through environmental buoys as compared to the medical model that assumes decline [5]. Both the ICF and Verbrugge stress the importance and bidirectionality of environmental as well as personal factors on individual health $[16,17]$. Environmental characteristics are hypothesized to limit or promote an individual's ability to complete purposeful actions and fulfill role expectations, affecting physical functioning and disability (see Figure 1).

Older adults may be more vulnerable to influence of their residential environment as they tend to travel outside their own neighborhoods less often than do younger adults and children who travel for work and school and tend to have a longer duration of exposure to neighborhood influences than younger individuals [5]. Declining physical and mental health, shrinking social networks, loss of social support, and increased fragility may also reduce the ability of older individuals to cope with environmental demands $[5,19,20]$. Therefore, neighborhood environment likely has a greater impact on the elderly than on those in other age groups and evidence suggests that supportive environments improve quality of life in older adults [21]. Lawton proposed several dimensions of environment that are important for older adults: personal environment (family, friends), suprapersonal environment (i.e., neighborhood racial or age composition), social environment (norms or values related to society or culture), and physical environment (e.g., built environment) [14]. The built environment is defined as the human-made or human-altered space in which individuals live out their daily lives [22] and is the focus of this paper.

Much of the existing research regarding neighborhoods and health has been conducted in younger or middle-aged adults and has focused on aspects of the environment other than the physical or built environment $[19,20,23]$. The built environment's effect on health has been conceptualized into three domains: transportation systems which include street networks and transit systems, land use patterns which includes density and land-use mix, and urban design which includes safety, attractiveness, and site design [18]. Transportation systems are defined as the network of physical infrastructure, such as its street network, transit systems, and trails (e.g., for jogging or biking,). Transportation systems influence how easy it is to travel through a neighborhood and get to places a person wants to go. Land use patterns reflect where and how residential, commercial, and industrial uses are distributed in a neighborhood. Density of land use represents an increased compactness of neighborhoods with easier access to pedestrian destinations. Urban design characteristics-such as number and width of traffic lanes, size and extensiveness of sidewalks, traffic calming devicesinfluence safety and attractiveness and ultimately decisions about whether or not to walk. Pleasant pedestrian environments that promote feelings of belonging to a neighborhood and trust in ones neighbors can be created through positive urban design [18]. In contrast, evidence of decay, such as vandalism and poorly maintained vacant lots, can reduce mobility by creating feelings of discomfort in one's neighborhood. All three of these domains can potentially impact mobility in the elderly (see Figure 1).
Use of self-reported measures of the environment is common in the existing literature but relies on participant's perception of problems rather than actual presence of barriers. Evidence consistently shows differences between objective and perceived measures of the local environment $[19,24]$. The two measurement types are likely capturing different constructs both of which are important in determining mobility of older adults. We focus on objective measures here in an attempt to summarize the direct effects of built environment factors as these can be ideal targets for public policy interventions.

The goal of this paper is to summarize the recent published literature on objective measures of the built environment and mobility or disability in older adults and provide a critical analysis of the limitations.

\section{Methods}

Searches of Medline and Web of Science were conducted for English-only articles published between 1 January, 1990 and 7 December, 2010 with the following keyword search terms: neighborhood, built environment, or physical environment and elderly, older adults, aging, mobility, disability, walking, or physical function. Additional articles were identified through consultation with experts and review of reference lists of included articles. Inclusion criteria were (1) the study population consisted of community-dwelling adults aged 60 years or older or if no range was provided, the average age was $\geq 65$ years, (2) built environment was objectively measured either through use of administrative datasets or research rater assessments, (3) outcomes included measures of mobility or disability and physical functioning as described in Verbrugge's disablement model [16]. Articles were excluded if they were a review or commentary or if they provided qualitative data only.

\section{Results}

We reviewed 31,596 abstracts for relevancy to this paper. Of these, 28 articles were reviewed for inclusion criteria, with seventeen articles meeting our criteria. Details of these studies are provided in Table 1. Four studies were longitudinal [25-28]; the remainder assessed cross-sectional associations. One study used nationally representative data from the USA [25] and one was conducted outside the USA [29]. Seven of the studies (41\%) were conducted in the Pacific Northwest [28, 30-35]. Enacted function, or walking in some form, was the most commonly assessed outcome, though there was little overlap in the way in which walking was assessed. Walking has been measured as specifically for exercise [35], for utilitarian purposes [30, 36], by frequency of neighborhood walking on a Likert scale [32-34], by whether individuals met physical activity recommendations for walking (>150 hours/week) $[27,29,37]$, and by other measures of walking frequency $[3,28,31]$. One study used accelerometers to directly measure the number of steps taken by participants in a day [38]. There were also a wide range of definitions for neighborhood, including specified 


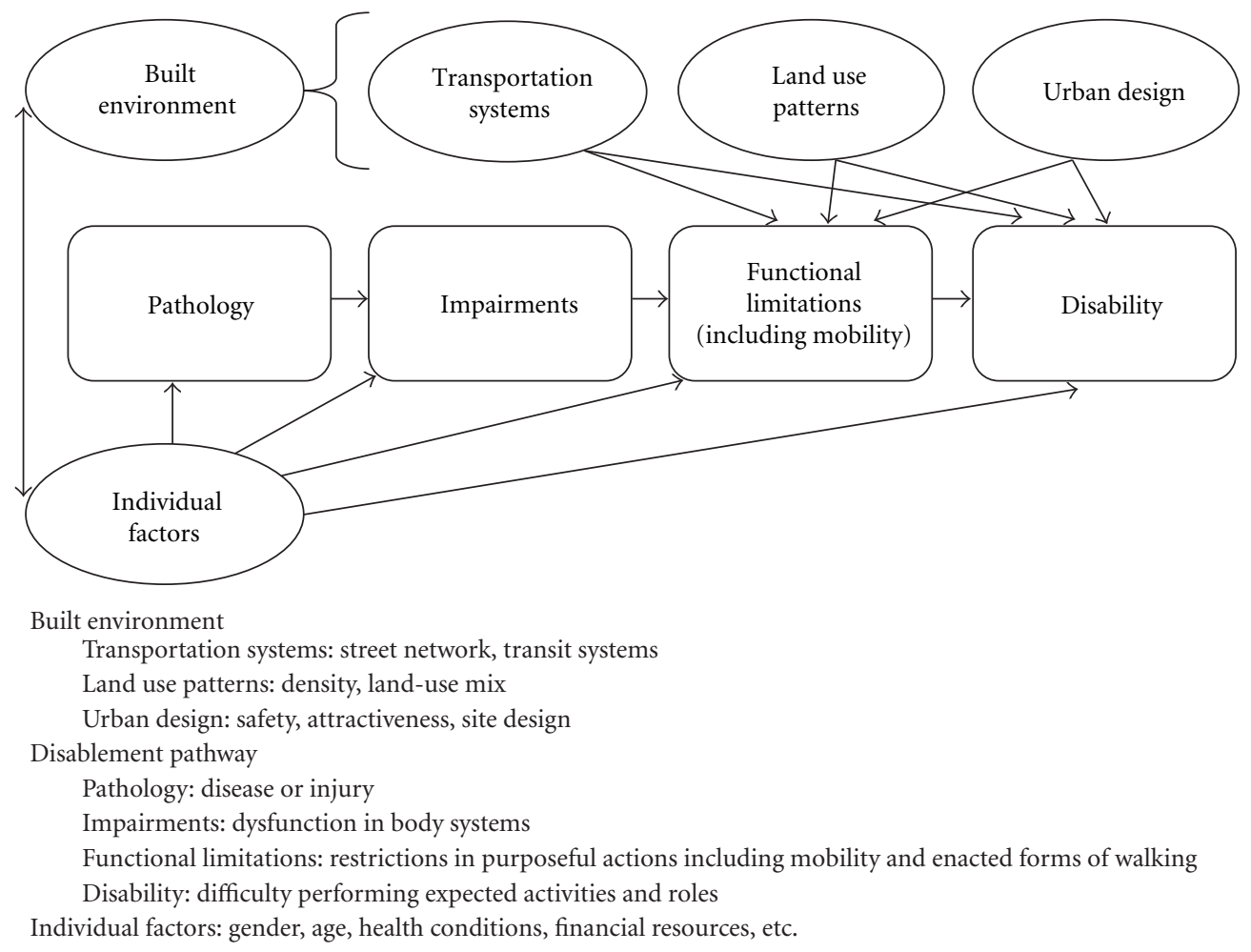

Figure 1: The role of the built environment in the disablement process (adapted from Verbrugge and Jette, 1994 [16] and Frank et al., 2003 $[18])$.

distances from an individual's home (i.e., quarter-mile radius), census tracts, and other administratively defined neighborhoods. Subgroup analyses were completed in only 5 studies, including gender [35], lower body functional status $[37,39]$, age $[25]$, and neighborhood socioeconomic status [28]. Fewer than half of the studies explicitly stated the theoretical framework or causal model that guided their research in the article $[26,28,30,34,37-39]$. Effect sizes tended to be small: approximately three-quarters of the statistically significant estimates had relative risks or odds ratios below 2.0 (range was 1.08 to 4.12 ).

3.1. Transportation Systems. Traffic-related street characteristics have been assessed in relation to mobility, with high-traffic volume positively associated with walking [31]. However, presence of through routes, representing hightraffic volume, was not associated with disability [40]. A high percentage of car commuters, indicating a greater reliance on driving rather than walking for transportation, was positively associated with increased walking difficulty among those aged 75 and older, but not among younger age groups [25]. Living within a specified area of Bogotá, Columbia in which streets are closed to vehicular traffic on Sundays and holidays, creating a pedestrian corridor, was positively associated with walking among older residents [29]. Proximity to walking paths and trails was associated with amount of daily walking [38] but not with frequency of neighborhood walking [32]. Finally, presence of nearby transit stops, providing access to areas outside the immediate neighborhood via public transit, was not associated with walking in two studies $[29,31]$. Street connectivity, indicating shorter blocks with more intersections and resulting in easier pedestrian links between two points, have been studied in relation to walking in older adults with mixed results. Nagel and colleagues and Satariano and colleagues found no association [31,37], Li and colleagues found a positive association [33], and Gomez and colleagues found an unexpected negative association [29]. Differences in study site, neighborhood definitions, and operationalization of walking likely accounted for some differences in results for street connectivity. Neighborhoods were specified differently in the four studies: those studies finding no association, Nagel et al. [31] and Satariano et al. [37], used a specified distance from homes, Li et al. [33] used city-defined neighborhoods, and Gomez et al. [29] used neighborhoods defined by socioeconomic status. Two discordant studies were conducted in the same city (Nagel et al. [31] and $\mathrm{Li}$ et al. [33]) and another two discordant studies both assessed walking as meeting physical activity recommendations (Satariano et al. [37] and Gomez et al. [29]).

3.2. Land Use Patterns. Housing density was associated with greater levels of walking [33] and with less disability among those with lower body functional limitations [39]. However, population density was not associated with increased walking difficulty over 15 years [25]. Mix of land use, representing proximity to a variety of destinations such as places of employment and retail establishments, has been assessed in 


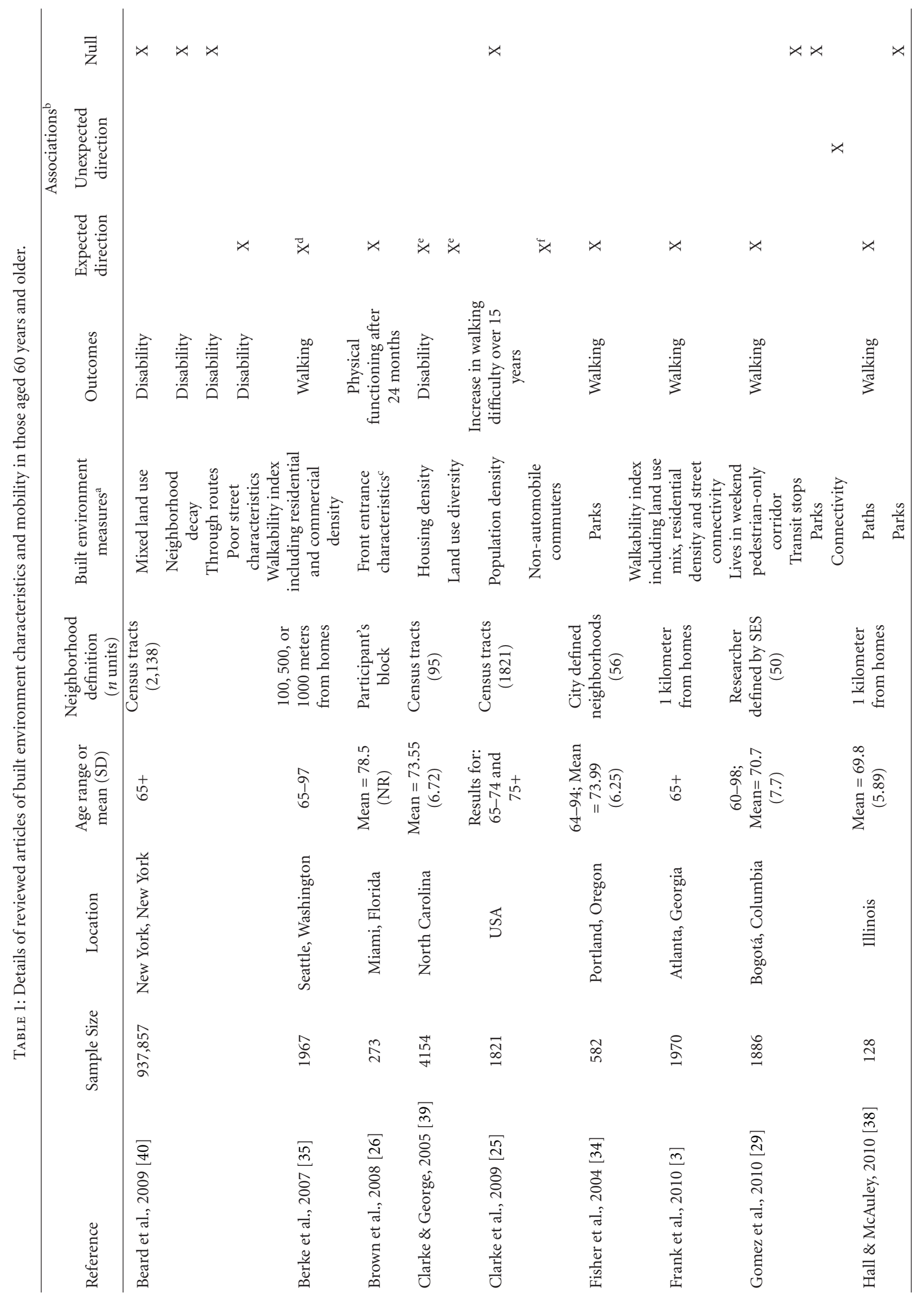




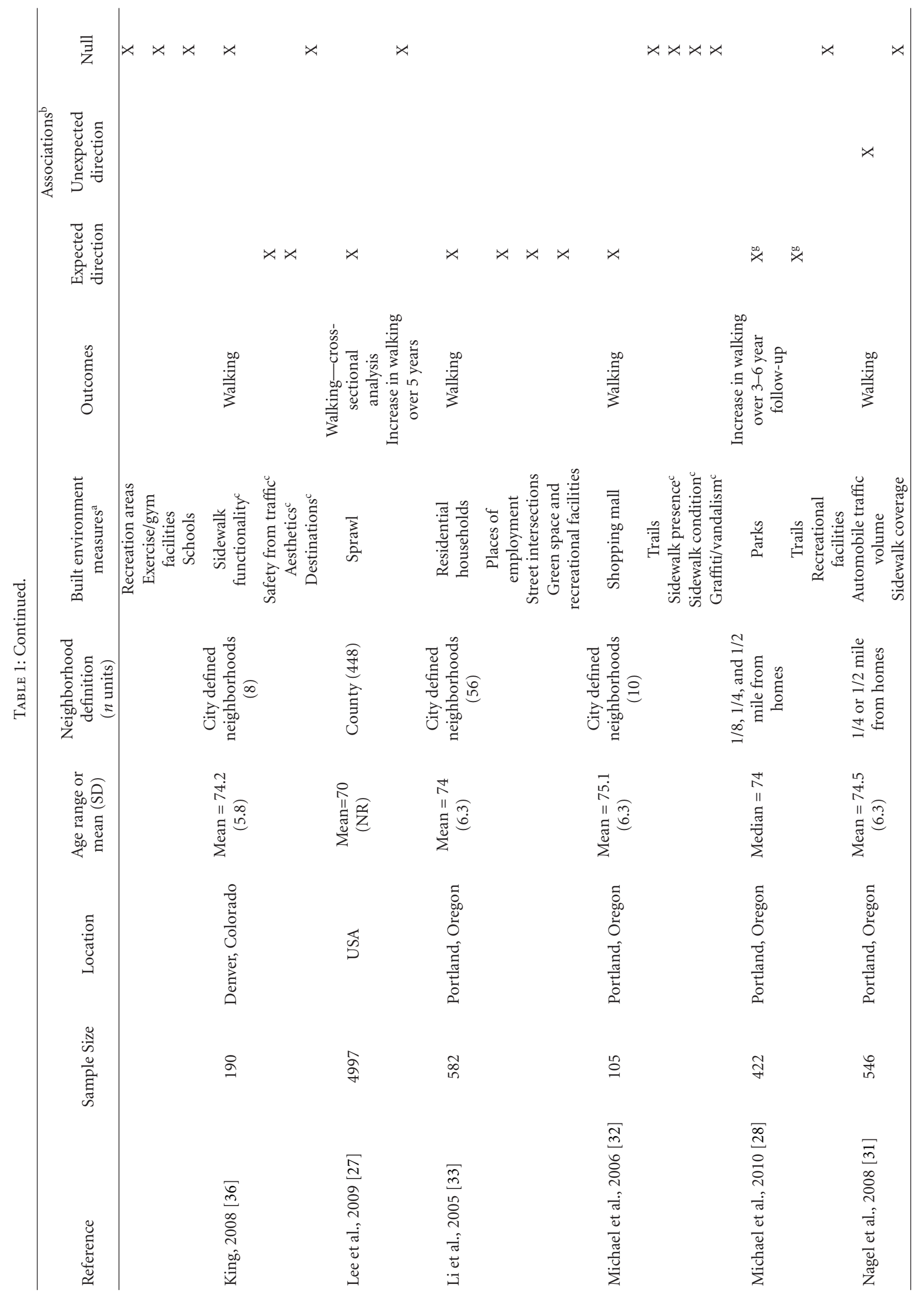




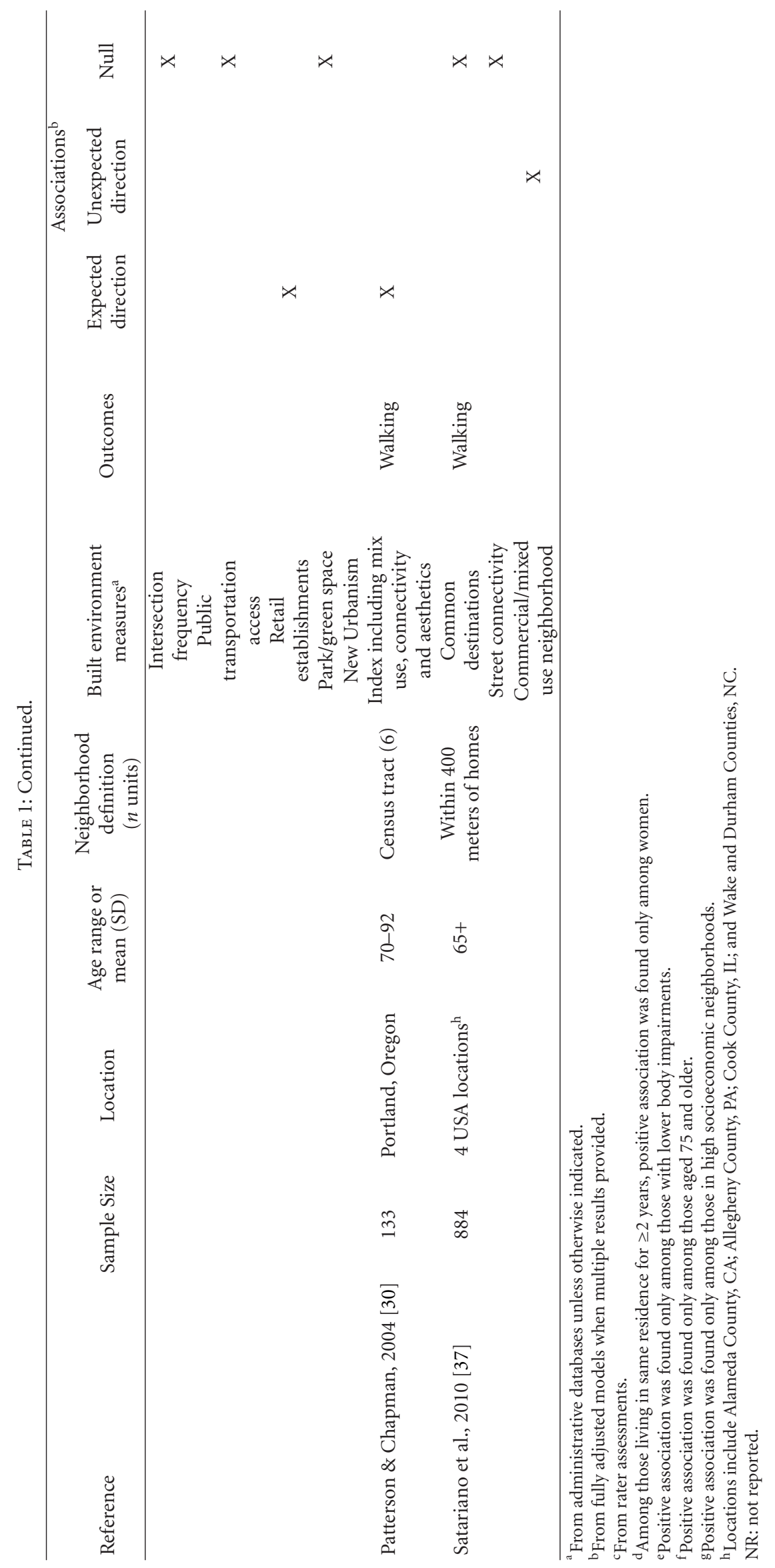


several studies with inconsistent results. More mixed land use was negatively associated with walking in one study [37], negatively associated with disability among those with lower body limitations in another [25], and unassociated with disability in a third [40].

Proximity to particular destinations has been widely assessed as a promoter of mobility among older adults. Presence of destinations may increase mobility by providing locations for recreational walking or by providing access to needed services such as grocery stores. No associations have been found between walking and presence of recreational facilities [28, 38], gyms [38], or schools [38]. In contrast, shopping malls and overall retail destinations have been associated with walking [31, 32]. More general measures of destinations have been used, including a measure of total places of employment which was positively associated with walking [33] and two separate measures of select destinations, including places such as retail businesses and parks, neither of which was associated with walking $[36,37]$.

3.3. Urban Design. Front entrance characteristics that promote social interactions, such as presence of a stoop and a shallow housing setback, were positively associated with physical functioning among older adults in a Hispanic neighborhood [26]. Neighborhood decay, represented by presence of graffiti or vandalism, was not associated with disability [40]. Graffiti or vandalism was associated with less walking in one study [36] but not associated in another [32]. Differences in results for the two walking studies cannot be attributed to size of the studies or to assessment of neighborhood as these were similar for both studies. However, the study finding no association evaluated walking as frequency of any neighborhood walking and the one reporting a positive association measured walking for errands only. Neither presence nor condition of sidewalks was associated with walking in several studies [31, 32, 36] but presence of safety measures for pedestrians against traffic was associated with walking [36]. Presence of parks has been positively associated with walking in two studies [33, 34], but no association was found in three others $[29,31,38]$. These inconsistencies may be a result of different localities, differences in neighborhood definitions, or differences in outcomes assessments as these all differed between those with positive findings and those with findings of no association. Michael and colleagues demonstrated a positive association between proximity to parks or paths and increases in walking over a 3-6-year period among men living in neighborhoods classified as having high socioeconomic status but not among those living in low socioeconomic status neighborhoods [28].

3.4. Composite Scores. For some study questions, a theoretical framework was used to guide the development of a built environment summary score. If the items in the summary score are similarly correlated with mobility, it may provide a more robust exposure than a single measure. Urban sprawl represents density of land use with more sprawling areas often having poorer accessibility and greater reliance on automobiles for transportation. Urban sprawl measured by census data was negatively associated with walking in crosssectional analysis, but no association was found between movement to an area classified as more or less sprawling and change in walking behavior [27]. Neighborhood walkability scores have included land use mix, residential density, street connectivity, park and trail presence, and vehicular traffic information. Frank and colleagues demonstrated a positive association between their walkability score and walking [3], whereas Berke and colleagues found a positive association only among women [35]. Patterson and Chapman developed a scale that combines elements of urban sprawl and walkability and found it was positively associated with walking among older adults in their study [30]. Another study reported negative street characteristics, defined as low density of intersections, few shade trees and few transit stops, were associated with greater disability [40].

\section{Conclusions}

The evidence provides empirical support for an association between aspects of the built environment and mobility in older adults. This paper suggests that built environment characteristics from three domains (transportation systems, land use patterns, and urban design) can impact both functional limitations and disability in positive and negative directions. However, it is still unclear if these associations represent direct influences on the disablement process. The most promising evidence points to high density of intersections, street and traffic conditions, and proximity to select destinations and green space as the most likely factors to impact mobility, though results have been inconsistent. These inconsistencies are likely due to differences in methodology. There are many differences between studies regarding neighborhood definition, exposure measurements, and outcome assessment.

Theoretical and methodological limitations are present in much of the existing literature on this topic. A number of papers lacked an explicit theoretical framework to guide determination of which neighborhood factors may impact mobility, at what spatial resolution effects should be assessed, and which individual and neighborhood level factors should be considered as confounders or mediators $[19,23,41]$. A majority of the existing literature is crosssectional, making causal inferences impossible $[19,20,22$, 24]. It is unknown whether individuals adapt their mobility based on environmental presses and buoys or whether they choose neighborhoods with fewer environmental demands as their potential mobility decreases. However, there is some evidence that an effect of built environment on walking persists even after accounting for selection factors [42].

It is unlikely that built environment characteristics affect all neighborhood residents in the same manner [19, 24]. Assessing subpopulations among older adults may prove important as the socially disadvantaged among themwomen, minorities, and those with low income-may be more vulnerable to environmental factors and have a higher propensity to live in disadvantaged neighborhoods $[5,20]$. 
In addition, results should be replicated in different localities as the existing research has been limited in its geographic scope and it is unclear if differences may be due to unique characteristics of a locality. Greater use of nationally representative data may help to confirm results and assess effect modification by location, although these studies may suffer from less detailed measures of the built environment.

Finally, this research field would benefit from use of broader measures of enacted mobility. This paper has identified walking measures as the primary measure of mobility; however, general mobility may be more important than walking, specifically. Use of assistive devices, public transportation, and personal automobiles allow for increased mobility and access to services such as healthcare and health$y$ foods [1]. General mobility assessments are available, such as the University of Alabama Birmingham Life-Space Assessment [43, 44]. Life-space is defined as the spatial area traveled by an individual in their daily life over a specified period of time. The Life-Space Assessment assesses extent of movement in the past month, how frequently that movement occurred, and whether assistance was used [43]. New technologies are also allowing objective measures of mobility through use of individual global positioning system (GPS) monitors [45]. GPS monitors do not rely on individual recall, allow assessment of individual trips into the community, and can provide information on specific location and speed of movement [45].

The current review is limited in that it addresses only objective measures of the built environment. While objective characteristics are more relevant to policy interventions [19], perceived measures capture important information about an individual's relationship with their environment. Perceived environmental measures can more easily assess quality and access to resources within the built environment that are often not apparent from objective data (e.g., residents underreport neighborhood parks because they are not safe to use). However, perceptions bundle psychosocial and behavioral factors with objective features of the environment [46]. Studies using perceived measures face a number of methodological challenges and bias issues that complicate their interpretation [47]. Perceived and objective measures are known to capture different conceptual aspects of many environmental factors [24]. Only five articles included in this review assessed perceived as well as objective measures, though only two included comparable variables [29, 32, 34, 37, 38]. More research is needed that allows direct comparison of the two types of measures and allows evaluation of independent and combined effects on mobility. An additional limitation was the use of broad search terms resulting in a large number of abstracts. The lack of dual review may have resulted in missed articles, but the use of reference lists as an additional review should have at least partially addressed this.

For this field to advance, research must have a strong theoretical framework, identify associations of the built environment with incident mobility restrictions, assess how changes in the built environment affect mobility, and characterize subpopulations among which these associations are strongest, areas that have not been adequately addressed in previous research. In general, effect sizes of associations between built environment characteristics and functioning in older adults are small to moderate. However, a large percentage of the population is exposed to these conditions, indicating that the potential public health impact of policy interventions could be great [48]. The advantage of population level interventions over those that target only high-risk individuals has been demonstrated $[49,50]$. In general, older adults wish to age in place, remaining in their homes rather than moving to potentially more accommodating locations [51]. In order to facilitate aging in place and maintaining quality of life as people age, it is important to understand the role of the built environment on mobility limitations and disability while addressing the limitations of the current body of evidence.

\section{References}

[1] S. C. Webber, M. M. Porter, and V. H. Menec, "Mobility in older adults: a comprehensive framework," The Gerontologist, vol. 50, no. 4, pp. 443-450, 2010.

[2] L. DiPietro, "Physical activity in aging: changes in patterns and their relationship to health and function," The Journals of Gerontology. Series A, vol. 56, no. 2, pp. 13-22, 2001.

[3] L. Frank, J. Kerr, D. Rosenberg, and A. King, "Healthy aging and where you live: community design relationships with physical activity and body weight in older Americans," Journal of Physical Activity and Health, vol. 7, supplement 1, pp. S82S90, 2010.

[4] P. Lampinen and E. Heikkinen, "Reduced mobility and physical activity as predictors of depressive symptoms among community-dwelling older adults: an eight-year follow-up study," Aging Clinical and Experimental Research, vol. 15, no. 3, pp. 205-211, 2003.

[5] T. A. Glass, J. L. Balfour et al., "Neighborhoods, aging, and functional limitations," in Neighborhoods and Health, I. Kawachi, L. F. Berkman et al., Eds., pp. 303-334, Oxford University Press, New York, NY, USA, 2003.

[6] M. E. Williams, "Identifying the older person likely to require long-term care services," Journal of the American Geriatrics Society, vol. 35, no. 8, pp. 761-766, 1987.

[7] B. W. Penninx, L. Ferrucci, S. G. Leveille, T. Rantanen, M. Pahor, and J. M. Guralnik, "Lower extremity performance in nondisabled older persons as a predictor of subsequent hospitalization," The Journals of Gerontology. Series A, vol. 55, no. 11, pp. M691-M697, 2000.

[8] J. B. Kuriansky, B. J. Gurland, and J. L. Fleiss, "The assessment of self care capacity in geriatric psychiatric patients by objective and subjective methods," Journal of Clinical Psychology, vol. 32, no. 1, pp. 95-102, 1976.

[9] J. M. Guralnik, E. M. Simonsick, L. Ferrucci et al., "A short physical performance battery assessing lower extremity function: association with self-reported disability and prediction of mortality and nursing home admission," Journal of Gerontology, vol. 49, no. 2, pp. M85-M94, 1994.

[10] D. B. Reuben, A. L. Siu, and S. Kimpau, "The predictive validity of self-report and performance-based measures of function and health," The Journal of Gerontology, vol. 47, no. 4, pp. M106-M110, 1992.

[11] L. P. Fried and J. M. Guralnik, "Disability in older adults: evidence regarding significance, etiology, and risk," Journal of the American Geriatrics Society, vol. 45, no. 1, pp. 92-100, 1997. 
[12] T. A. Glass, "Conjugating the "tenses" of function: discordance among hypothetical, experimental, and enacted function in older adults," The Gerontologist, vol. 38, no. 1, pp. 101-112, 1998.

[13] A. E. Patla and A. Shumway-Cook, "Dimensions of mobility: defining the complexity and difficulty associated with community mobility," Journal of Aging and Physical Activity, vol. 7, no. 1, pp. 7-19, 1999.

[14] M. Lawton, "Competence, environmental press, and the adaptation of older people," in Aging and the Environment, M. Lawton, P. Windley, and T. Byerts, Eds., Springer, New York, NY, USA, 1982.

[15] M. P. Lawton, "Environment and other determinants of wellbeing in older people," The Gerontologist, vol. 23, no. 4, pp. 349-357, 1983.

[16] L. M. Verbrugge and A. M. Jette, "The disablement process," Social Science and Medicine, vol. 38, no. 1, pp. 1-14, 1994.

[17] World Health Organization, International Classification of Functioning, Disability, and Health: ICF Short Version, vol. iii, World Health Organization, Geneva, Switzerland, 2001.

[18] L. D. Frank, P. O. Engelke, and T. L. Schmid, Health and Community Design: The Impact of the Built Environment on Physical Activity, Island Press, Washington, DC, USA, 2003.

[19] I. H. Yen, Y. L. Michael, and L. Perdue, "Neighborhood environment in studies of health of older adults: a systematic review," American Journal of Preventive Medicine, vol. 37, no. 5, pp. 455-463, 2009.

[20] P. Clarke and E. R. Nieuwenhuijsen, "Environments for healthy ageing: a critical review," Maturitas, vol. 64, no. 1, pp. 14-19, 2009.

[21] T. Sugiyama and C. W. Thompson, "Outdoor environments, activity and the well-being of older people: conceptualising environmental support," Environment and Planning, vol. 39, no. 8, pp. 1943-1960, 2007.

[22] A. Renalds, T. H. Smith, and P. J. Hale, "A systematic review of built environment and health," Family and Community Health, vol. 33, no. 1, pp. 68-78, 2010.

[23] S. Macintyre, A. Ellaway, and S. Cummins, "Place effects on health: how can we conceptualise, operationalise and measure them?" Social Science and Medicine, vol. 55, no. 1, pp. 125-139, 2002.

[24] I. Kawachi and L. F. Berkman, Neighborhoods and Health, Oxford University Press, New York, NY, USA, 2003.

[25] P. Clarke, J. A. Ailshire, and P. Lantz, "Urban built environments and trajectories of mobility disability: findings from a national sample of community-dwelling American adults (1986-2001)," Social Science and Medicine, vol. 69, no. 6, pp. 964-970, 2009.

[26] S. C. Brown, C. A. Mason, T. Perrino et al., "Built environment and physical functioning in hispanic elders: the role of 'eyes on the street," Environmental Health Perspectives, vol. 116, no. 10, pp. 1300-1307, 2008.

[27] I. M. Lee, R. Ewing, and H. D. Sesso, "The built environment and physical activity levels. The Harvard alumni health study," American Journal of Preventive Medicine, vol. 37, no. 4, pp. 293-298, 2009.

[28] Y. L. Michael, L. A. Perdue, E. S. Orwoll, M. L. Stefanick, and L. M. Marshall, "Physical activity resources and changes in walking in a cohort of older men," American Journal of Public Health, vol. 100, no. 4, pp. 654-660, 2010.

[29] L. F. Gomez, D. C. Parra, D. Buchner et al., "Built environment attributes and walking patterns among the elderly population in Bogota," American Journal of Preventive Medicine, vol. 38, no. 6, pp. 592-599, 2010.
[30] P. K. Patterson and N. J. Chapman, "Urban form and older residents' service use, walking, driving, quality of life, and neighborhood satisfaction," American Journal of Health Promotion, vol. 19, no. 1, pp. 45-52, 2004.

[31] C. L. Nagel, N. E. Carlson, M. Bosworth, and Y. L. Michael, "The relation between neighborhood built environment and walking activity among older adults," American Journal of Epidemiology, vol. 168, no. 4, pp. 461-468, 2008.

[32] Y. Michael, T. Beard, D. Choi, S. Farquhar, and N. Carlson, "Measuring the influence of built neighborhood environments on walking in older adults," Journal of Aging and Physical Activity, vol. 14, no. 3, pp. 302-312, 2006.

[33] F. Li, K. J. Fisher, R. C. Brownson, and M. Bosworth, "Multilevel modelling of built environment characteristics related to neighbourhood walking activity in older adults," Journal of Epidemiology and Community Health, vol. 59, no. 7, pp. 558-564, 2005.

[34] K. J. Fisher, F. Li, Y. Michael, and M. Cleveland, "Neighborhood-level influences on physical activity among older adults: a multilevel analysis," Journal of Aging and Physical Activity, vol. 12, no. 1, pp. 45-63, 2004.

[35] E. M. Berke, T. D. Koepsell, A. V. Moudon, R. E. Hoskins, and E. B. Larson, "Association of the built environment with physical activity and obesity in older persons," American Journal of Public Health, vol. 97, no. 3, pp. 486-492, 2007.

[36] D. King, "Neighborhood and individual factors in activity in older adults: results from the neighborhood and senior health study," Journal of Aging and Physical Activity, vol. 16, no. 2, pp. 144-170, 2008.

[37] W. A. Satariano, S. L. Ivey, E. Kurtovich et al., "Lower-body function, neighborhoods, and walking in an older population," American Journal of Preventive Medicine, vol. 38, no. 4, pp. 419-428, 2010.

[38] K. S. Hall and E. McAuley, "Individual, social environmental and physical environmental barriers to achieving 10000 steps per day among older women," Health Education Research, vol. 25, no. 3, pp. 478-488, 2010.

[39] P. Clarke and L. K. George, "The role of the built environment in the disablement process," American Journal of Public Health, vol. 95, no. 11, pp. 1933-1939, 2005.

[40] J. R. Beard, S. Blaney, M. Cerda et al., "Neighborhood characteristics and disability in older adults," The Journals of Gerontology. Series B, vol. 64, no. 2, pp. 252-257, 2009.

[41] G. O. Cunningham and Y. L. Michael, "Concepts guiding the study of the impact of the built environment on physical activity for older adults: a review of the literature," American Journal of Health Promotion, vol. 18, no. 6, pp. 435-443, 2004.

[42] S. Handy, X. Y. Cao, and P. L. Mokhtarian, "Self-selection in the relationship between the built environment and walking: empirical evidence from Northern California," Journal of the American Planning Association, vol. 72, no. 1, pp. 55-74, 2006.

[43] P. S. Baker, E. V. Bodner, and R. M. Allman, "Measuring lifespace mobility in community-dwelling older adults," Journal of the American Geriatrics Society, vol. 51, no. 11, pp. 16101614, 2003.

[44] C. Peel, P. S. Baker, D. L. Roth, C. J. Brown, E. V. Bodner, and R. M. Allman, "Assessing mobility in older adults: the UAB sudy of aging life-space assessment," Physical Therapy, vol. 85, no. 10, pp. 1008-1019, 2005.

[45] S. C. Webber and M. M. Porter, "Monitoring mobility in older adults using global positioning system (GPS) watches and accelerometers: a feasibility study," Journal of Aging and Physical Activity, vol. 17, no. 4, pp. 455-467, 2009. 
[46] A. Bowling and M. Stafford, "How do objective and subjective assessments of neighbourhood influence social and physical functioning in older age? Findings from a British survey of ageing," Social Science and Medicine, vol. 64, no. 12, pp. 25332549, 2007.

[47] S. W. Raudenbush and R. J. Sampson, "Ecometrics: toward a science of assessing ecological settings, with application to the systematic social observation of neighborhoods," Sociological Methodology, vol. 29, no. 1, pp. 1-41, 1999.

[48] K. E. Pickett and M. Pearl, "Multilevel analyses of neighbourhood socioeconomic context and health outcomes: a critical review," Journal of Epidemiology and Community Health, vol. 55, no. 2, pp. 111-122, 2001.

[49] J. B. McKinlay, "The promotion of health through planned sociopolitical change: challenges for research and policy," Social Science and Medicine, vol. 36, no. 2, pp. 109-117, 1993.

[50] G. Rose, "Sick individuals and sick populations," International Journal of Epidemiology, vol. 14, no. 1, pp. 32-38, 1985.

[51] A. E. Scharlach, "Creating aging-friendly communities," Generations, vol. 33, no. 2, pp. 5-11, 2009. 


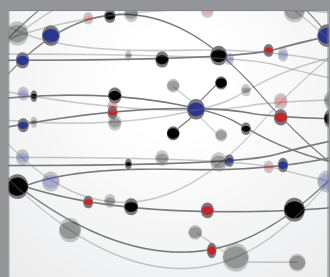

The Scientific World Journal
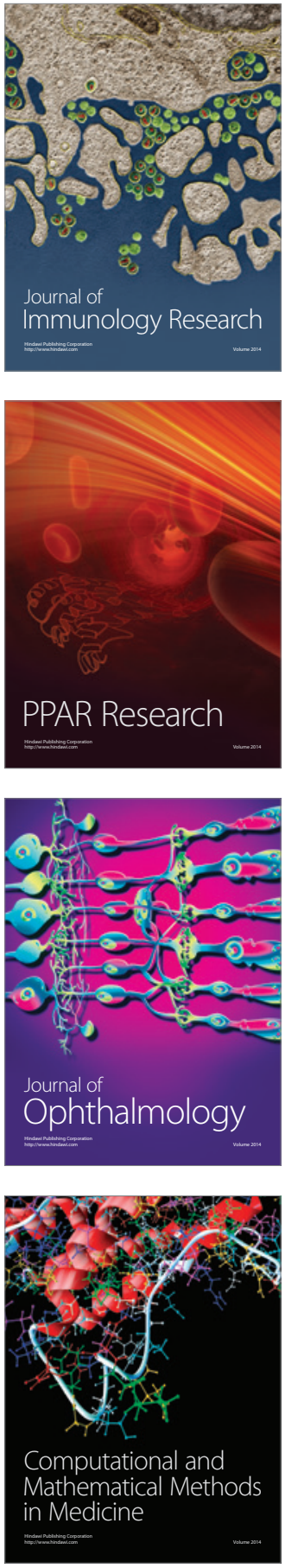

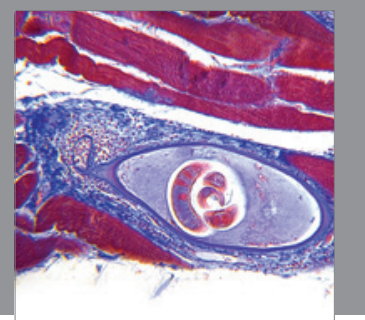

Gastroenterology

Research and Practice
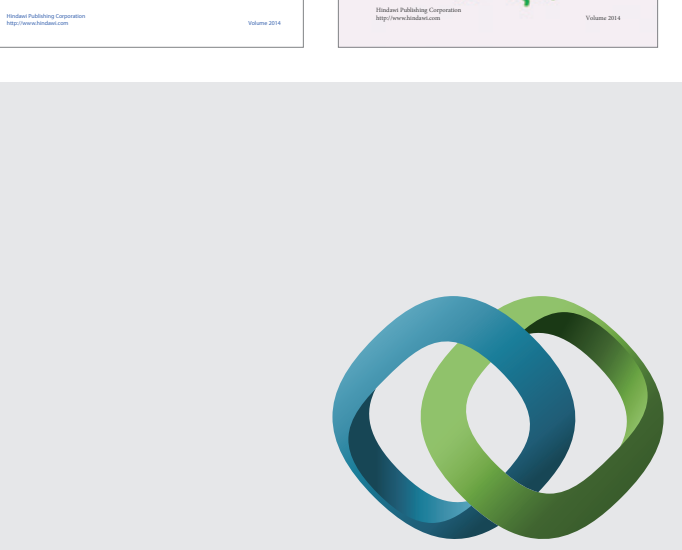

\section{Hindawi}

Submit your manuscripts at

http://www.hindawi.com
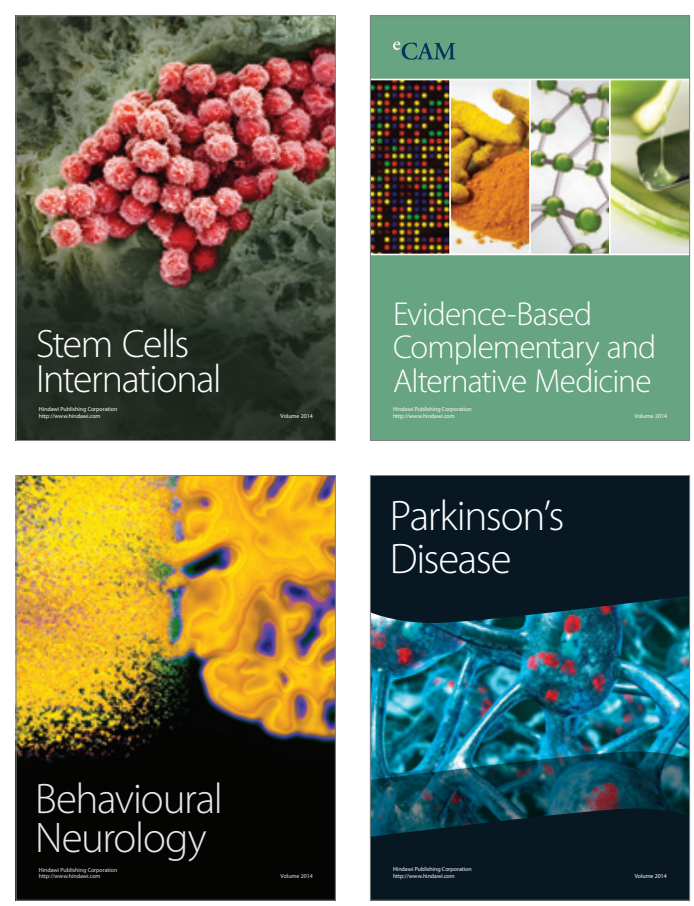

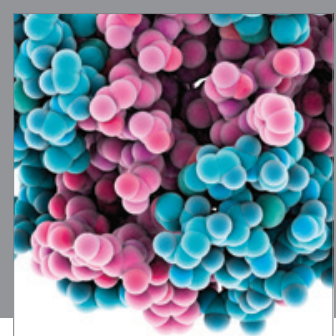

Journal of
Diabetes Research

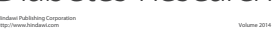

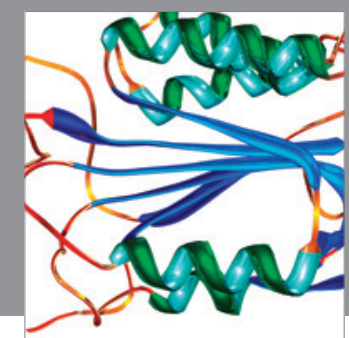

Disease Markers
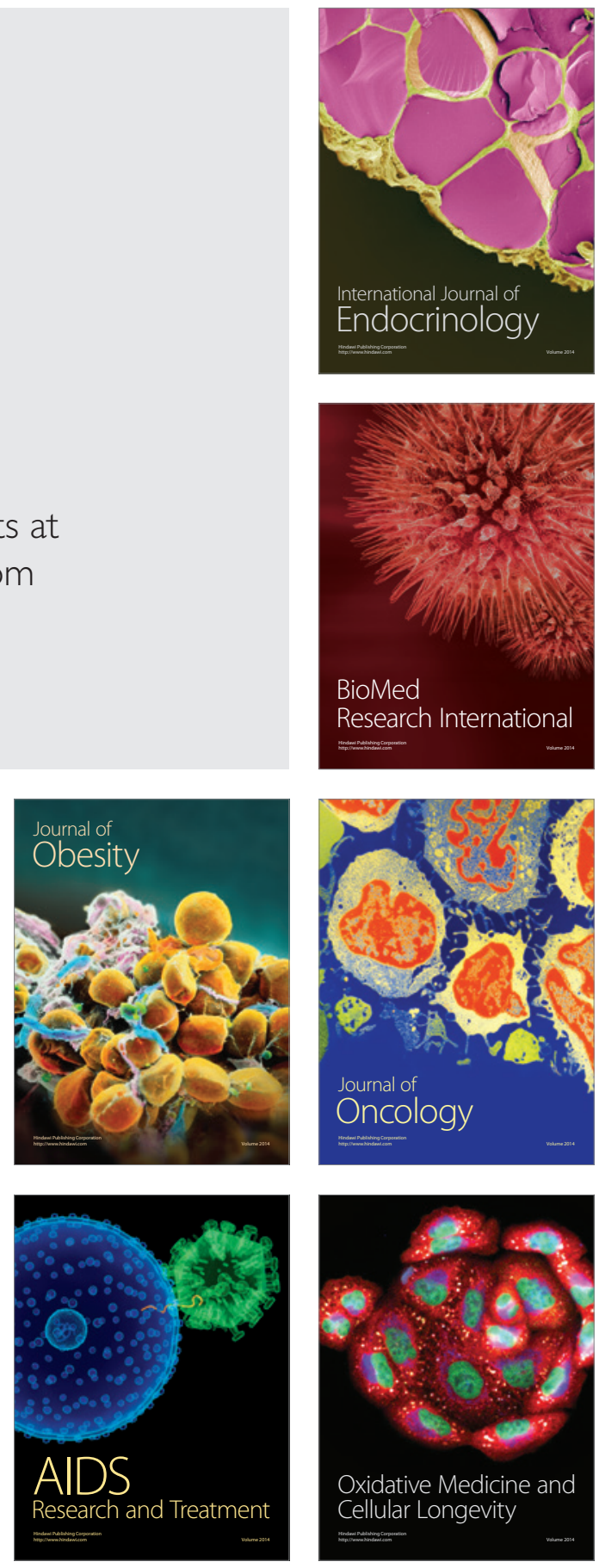